\title{
Representation, Enaction, Religion. Different Models of Cognition and Their Implications for the Cognitive Study of Religions ${ }^{1}$
}

\author{
Matylda Ciołkosz \\ Institute for the Study of Religions \\ Jagiellonian University
}

\begin{abstract}
The aim of the paper is to consider the implications of applying the enactive approach to cognition within the study of religions. This approach is discussed as an alternative to the classical, cognitivist stance predominant among the proponents of cognitive science of religion (CSR). The most popular model within CSR is that of cognition as manipulation of concepts. The key assumptions of this model limit the understanding of religion to a system of beliefs. Applying an alternative model - of cognition as enaction - may contribute to creating a more comprehensive model of religion, taking into consideration its pre-conceptual origins. Using the category of representation as the departure point, the author juxtaposes the cognitivist and the enactive stance, showing how substituting the former with the latter necessarily changes the construal of religious activity and thinking.
\end{abstract}

Key words: cognitive science of religion, enactivism, embodied cognition, representationism, ritual, religions of India

Słowa kluczowe: religioznawstwo kognitywne, enaktywizm, poznanie ucieleśnione, reprezentacjonizm, rytuał, religie Indii

1 There are a few reasons for the use of term cognitive study of religions in the title, instead of the generally accepted cognitive science of religion (CSR). First, the author is a scholar of religions attempting to apply the cognitive stance, and not a cognitive scientist studying religion. Therefore in the phrase in question the term study of religions is the departure point, while the adjective cognitive is its qualifier. Secondly, the author has no ambition whatsoever to be a scientist, and has serious doubts whether religion can be thoroughly explained through science at all. Lastly, CSR has become a household phrase associated with a particular theory of religion grounded in a particular model of mentality and cognition. Since the approach proposed in this paper does not make use of this model, it does not place the present discussion within the field of CSR in a strict sense. 


\section{Introduction}

Cognitive science of religion (CSR) has gained a strong presence in the academic milieu in recent years. It has been praised by many for providing what seems like an easily operationalised theory of religion. It has also been scorned by equally many for advocating a simplified - if not simplistic - model of religion. As the advocates of CSR keep devising new experiments to verify their theses, and its opponents question the explanatory value of such pursuits, it is important to realise that the model of religion proposed by CSR is not the only option available within the cognitive paradigm. If one steps back and changes the applied model of cognition, it becomes not only possible, but in fact necessary to rethink religion from scratch. The purpose of this paper is to suggest how the basic assumptions about religion must be rephrased, when the understanding of cognition changes from cognitivist to enactive. The central category in the discussion is that of representation, here understood simply as a cognitive system's internal construal of an external phenomenon.

\section{Cognitivism: localised minds and cognition as representation}

All the dominant views on religion within CSR are grounded in so-called cognitivism, ${ }^{2}$ according to which the mind is a localised, virtual entity, and cognition is computational processing of mental representations. This model is implicit not only in the classical view advocated by Pascal Boyer, ${ }^{3}$ Scott Atran ${ }^{4}$ and their descendants, but also in such modified views as the one proposed by Armin W. Geertz. ${ }^{5}$ The groundwork for cognitivism was provided by Jerry Fodor, who over three decades ago proclaimed that the "typical function of cognitive mechanisms is the transformation of mental representations. ${ }^{\prime 6}$ Fodor described a tripartite structure of mental processes. Input systems register perceptual information and analyse it, supplying representations of the environment. Transducers change the format of these representations, making them available for further processing. Central processes are responsible for problem solving based on the transduced information from the input systems and on background knowledge. Such problem solving involves computation based on "best

${ }^{2}$ See F. Varela, E.T. Thompson, E. Rosch, The Embodied Mind. Cognitive Science and Human Experience, Cambridge 1991, pp. $7 \mathrm{ff}$.

${ }^{3}$ P. Boyer, The Naturalness of Religious Ideas: A Cognitive Theory of Religion, Berkeley 1994; idem, Religion Explained. The Evolutionary Origins of Religious Thoughts, New York 2001.

${ }^{4}$ S. Atran, In Gods We Trust. The Evolutionary Landscape of Religion, Oxford 2002.

${ }^{5}$ See A.W. Geertz, Brain, Body and Culture: A Biocultural Theory of Religion, "Method and Theory in the Study of Religion" 2010, 22, pp. 304-321. This claim will be elaborated further on. Even though Geertz endorses embodied cognition, his approach is in fact a variety of cognitivism, referred to by Daniel D. Hutto and Erik Myin as Conservative Embodied Cognition (see D.D. Hutto, E. Myin, Radicalizing Enactivism. Basic Minds without Content, Cambridge, MA 2013, pp. 9 ff.).

${ }^{6}$ J.A. Fodor, The Modularity of Mind: An Essay on Faculty Psychology, Cambridge, MA 1983, p. 13. 
hypotheses," and results in "fixation of belief." " What is notable in this model is that perception (passive acquiring of fixed information from the environment) and cognition (processing of that information) are construed as distinct processes. Secondly, the mind's stance is deemed propositional (i.e. the involved representations are believed to have assigned truth-value).

An important notion for the proponents of classical CSR is that of the modularity of mind. First advanced by Fodor, ${ }^{9}$ it meant that some input systems function as modules - they are specialised computational mechanisms hardwired in the brain, processing information coming from distinct perceptual domains. It is noteworthy that Fodor postulates separate input systems for processing linguistic information e.g. he suggests that some auditory modules might be responsible for "assign[ing] grammatical descriptions to token utterances." ${ }^{10}$ What this means is that linguistic processing (or at least parts thereof) is placed at the same level of cognition as, for example, other forms of auditory analysis. Linguistic cognition is construed as a distinct process initiated already at the level of input analysis in modules especially assigned to perform the task.

The most important features of input modules are their domain-specificity (they are specialised to process a limited range of information) and encapsulation (they are insulated from other modules and from non-perceptual background knowledge). Moreover, their development proceeds according to endogenously determined patterns - "mental architecture is innately specified and... the ontogeny of cognition is primarily the unfolding of a genetic program." ${ }^{11}$ In other words, the modularity of mind is fixed by evolution.

According to Fodor, modularity does not extend onto central processes. ${ }^{12}$ The latter are general problem-solvers, whose operation is sensitive to external phenomena. They are isotropic (they draw inferences based on input from different input systems) and Quineian (their output is sensitive to the outputs of all input systems). This view was challenged by Dan Sperber, according to whom both perceptual and conceptual processes (the latter compared to Fodor's central processes) are modular. ${ }^{13}$ The trick is that perceptual and conceptual domains simply do not overlap - domain-specific conceptual mechanisms get their inputs from several input mechanisms. Thus, they remain informationally encapsulated, "while chains of inference [...] take a conceptual premise from one module to the next [...] integrat[ing] the contribution of each in some final conclusion." ${ }^{14}$ Although innately determined, conceptual modules exhibit certain plasticity. More general modules (e.g. specialised in living-kind recognition) may produce more specialised micro-modules (e.g. specialised in recognition of dogs

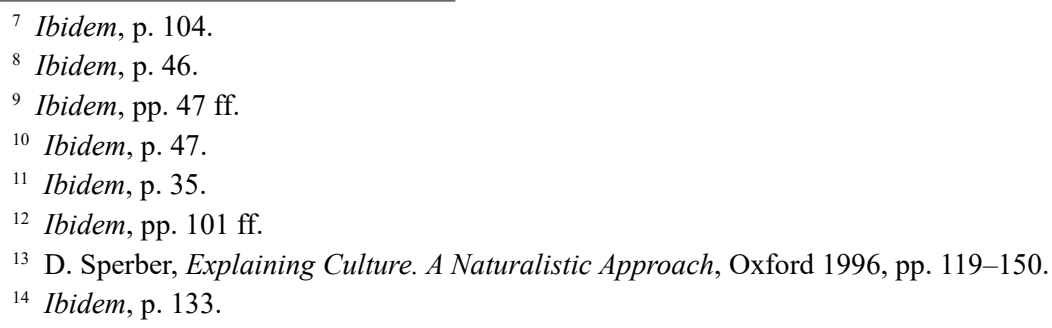


or humans). ${ }^{15}$ Moreover, even though conceptual modules have their evolutionarily assigned proper domains, they may be triggered by (potentially much broader) actual domains. Sometimes proper domains may be altogether removed from the environment, so actual domains no longer overlap with them.

To summarise the cognitivist stance, it presents the mind as a localised virtual machine, and cognition as localised manipulation of representations of a pre-given world. The outcomes of cognition - beliefs - are propositional in nature. Finally, algorithms for cognition are evolutionarily acquired and innate - the contents processed may change, but not the algorithms themselves. In a nutshell, cognition is theorising (even if automatic and inaccessible to the theoriser's awareness), which may potentially be followed by action (if the belief acquired as a result of this theorising asks for one).

\section{Religion according to cognitivism: representing that which isn't}

The length of this paper does not allow for a detailed discussion of the cognitivist understanding of religion. But since literature devoted to the topic is abundant, a brief summary seems sufficient. According to classical CSR, religion is a commitment to a socially shared system of representations of a specific kind. Religious representations are of anthropomorphic, ${ }^{16}$ moderately counterintuitive (MCI) agents with unlimited access to strategic information, ${ }^{17}$ reigning over human existential anxieties, such as death and deception..$^{18}$ With such definition of religion, the key problem that needs solving is that religious propositions (e.g. anthropomorphic gods exists and control our lives) are counterfactual. In other words, explaining religion means explaining why there is a widespread commitment to representations of something that isn't. The explanation offered is that religious representations are parasitic of our hardwired mental susceptibilities (i.e. by-products of dispositions selected during evolution).$^{19}$ To put it bluntly, religion is an inevitable consequence of fairly rigid, unreflective, biologically constrained modes of thinking.

The above does not mean that the cognitivist approach ignores the practical aspect of religion. As Boyer acknowledges, "religion is a rather practical thing," ${ }^{20}$ by which he means that it involves forms of activity aimed at fulfilling particular needs. But the interpretation of this activity is determined by the representationalist stance: religious

${ }^{15}$ Sperber's proposal opposes the experimentally confirmed model of concept formation proposed by Eleanor Rosch (See E. Rosch, Principles of Categorization [in:] Concepts. Core Readings, E. Margolis, S. Laurence (eds.), Cambridge, MA 1999 [1976], pp. 189-206). According to Rosch, the most basic categories acquired during ontogeny are middle-level categories (e.g. dog or cat). More abstract, superordinate categories (such as animal or living organism) are developed through generalisation on the basis of the basic ones. Notably, Fodor supports Rosch's model (J.A. Fodor, op. cit., p. 94).

16 See S. Guthrie, Faces in the Clouds. A New Theory of Religion, Oxford 1993.

${ }^{17}$ See P. Boyer, Religion Explained...

${ }^{18}$ See S. Atran, op. cit.

19 See D. Sperber, op. cit., pp. $80 \mathrm{ff}$.

${ }^{20}$ P. Boyer, Religion Explained..., p. 138. 
rituals are a consequence of representing gods, ancestors and other culturally postulated beings as MCI agents. They are forms of interactions with these agents determined by the way they are construed.

A renowned cognitivist account of ritual is that offered by Robert McCauley and E. Thomas Lawson. According to the authors' theory of ritual competence,${ }^{21}$ representing ritual action employs the same system as representing action in general. This system, however, is supplemented by representations of so-called culturally postulated superhuman (CPS) agents, who may play the role of special agents or special patients in different ritual contexts. ${ }^{22}$ In this interpretation, religious representations precede (and justify) ritual performance, and the notion of representation (of particular entities and general actions) plays a central role. Once again, first comes the thinking, then the acting.

The account of ritual proposed by Harvey Whitehouse takes on a different perspective. ${ }^{23}$ The author acknowledges the pro-social aspect of religion and ritual, seeking a relation between different modes of religiosity and the development of different economic and political systems. According to Whitehouse, the imagistic mode involves sporadic, highly arousing rituals, during which doctrines are transmitted as iconic imagery through triggering episodic memory. ${ }^{24}$ In doctrinal mode, on the other hand, a propositional body of doctrines is transmitted through regular, routinised worship involving low stimulation, and triggering semantic memory. While the former mode may induce identity fusion and support the hunter-gatherer economy, the latter, through promoting group identification, supports agriculture-based economies. ${ }^{25} \mathrm{All}$ in all, this account presents ritual as a subsidiary mechanism, supporting different modes of representation (imagistic vs propositional) and routes of reflection. Even if emotion-inducing aspects of ritual activity are accounted for, these emotions promote further reflection, e.g. concerning the relation between a participant and their community. In short, religion is still about thinking - sometimes in propositions, and at other times in images.

\section{Enactivism: cognition as enaction}

Enactivism as a separate paradigm within cognitive science emerged in the early 1990s, and its classical exposition was supplied by Francisco Varela, Evan Thompson, and Eleanor Rosch. In the authors' account, "[c]ognition is not the representation of a pregiven world by a pregiven mind but $[\ldots .$.$] the enactment of a world and a mind$

${ }^{21}$ R.N. McCauley, E.T. Lawson, E. Thomas, Bringing Ritual to Mind, Cambridge 2004, pp. 4 ff.

${ }^{22}$ Ibidem, pp. $26 \mathrm{ff}$.

${ }^{23}$ See e.g. H. Whitehouse, Arguments and Icons. Divergent Modes of Religiosity, Oxford 2000.

${ }^{24}$ See E. Tulving, Episodic and Semantic Memory [in:] Organization of Memory, E. Tulving, W. Donaldson (eds.), New York 1972, pp. 381-402.

${ }^{25}$ H. Whitehouse, J.A. Lanman, The Ties That Bind Us: Ritual, Fusion, and Identification, "Current Anthropology” 2014, 55(6), pp. 674-695. 
on the basis of a history of the variety of actions that a being in the world performs." 26 This is a fairly general statement that allows for a variety of interpretations, some of which may not be much different from the cognitivist stance. ${ }^{27}$ Therefore some qualification is needed to establish what enaction really means. A valuable account of enactivism was provided in 2010 by Ezequiel A. Di Paolo, Marieke Rohde, and Hanne De Jaegher, ${ }^{28}$ who describe the fivefold core of the enactive approach. At first, they list autonomy, meaning that a cognitive system is operationally closed, it sets up the rules of its own activity (rather than being innately equipped with them) and engages with the environment as an agent. The last statement means that a system not only reacts to stimuli, but it also participates in a dynamic exchange with its milieu, determining the conditions thereof. According to this view, cognition involves continuous feedback between the agent and its surroundings, rather than internal processing of passively received information.

As the second element, the authors list sense-making, meaning that through cognitive activity systems "cast a web of significance" 29 on their world by specifying the features they detect. The notion of significance may cause some confusion, as not all strands of enactivism endorse the view that all cognitive processes involve generation of meaning. However, what is agreed upon is that "sense is not an invariant present in the environment that must be retrieved [...] [but] the outcome of the dialog between [...] organisms in action and the dynamics of the environment." ${ }^{30}$

The central pillar of enactivism is the notion of emergence. A property is emergent when, rather than characterising one or more elements of a system, it arises as a result of the interconnection and interaction between those elements. Should even a single element be removed, the property wanes. In other words, the property does not have an ontological status separate from the processes that constitute it. According to Di Paolo et al., a system's autonomy is an emergent property - an agent's precarious identity arises out of ongoing processes. Meaning is also emergent, as it can be found neither in the environment nor in the internal dynamics of the agent, but [in] "the relational domain established between the two." 31 Along these lines, the mind "emerges from the self-organizing and self-creating activities of living organisms." 32 Not only is it a process rather than a virtual apparatus, but it is also an ongoing result of cognitive activities rather than a pregiven faculty making these activities possible. To underscore this claim over again, enaction implies that what is mental emerges in the process of bodily presence and animation within an environment.

${ }^{26}$ E. Varela, E.T. Thompson, E. Resch, op. cit., p. 9.

${ }^{27}$ For an in-depth discussion of the gradation of relations between enactivism and cognitivism, see D.D. Hutto, E. Myin, op. cit.

${ }^{28}$ E.A. Di Paolo, M. Rohde, H. De Jaegher, Horizons for the Enactive Mind: Values, Social Interaction, and Play [in:] Enaction. Toward a New Paradigm for Cognitive Science, J. Stewart, O. Gapenne, E.A. Di Paolo (eds.), Cambridge, MA 2010, pp. 33-87.

29 Ibidem, p. 39.

30 Ibidem, pp. 39-40.

${ }^{31}$ Ibidem, p. 40.

32 D.D. Hutto, E. Myin, op. cit., p. 32. 
Special attention should be given to the notion of embodiment underlying the enactive stance, as it may easily be underestimated. To claim that cognition is $\mathrm{em}$ bodied does not simply mean that the body is the mind's extension (i.e. an external tool aiding cognition) or a vessel for the mind alternative (or complementary) to the brain. The embodiment of mind and cognition implies that what is mental emerges in the process of bodily animation within an environment. As Gilbert Ryle gracefully put it over six decades ago, "'the mind is [not] its own place' [...] for the mind is not even a metaphorical 'place'. On the contrary, the chessboard, the platform, the scholar's desk, the judge's bench, the lorry-driver's seat, the studio and the football field are among its places, [as t]hese are where people work and play stupidly or intelligently." ${ }^{33}$ In the words of Hutto and Myin, minds are not merely extended, but extensive (i.e. fundamentally and constitutively world-involving). ${ }^{34}$

The final item on Di Paolo et al.'s list is experience as the source of cognitive proficiency. Systems become efficient agents not by virtue of being equipped or having gained information about their milieu, but through undergoing transformation in the process of enacting the relation with it.

\section{Enactivism and representation}

The relationship between enactivism and representationalism is ambiguous, as different authors present different stances towards the problem of (representational) content. The present discussion is best suited with so-called Radical Embodied Cognition (REC) ${ }_{35}^{35}$ as it provides the most stripped-down foundation for reconstructing the understanding of religion.

According to Hutto and Myin, basic cognition (any process involving intentionality) and basic mentality (any process involving intentionality and phenomenality) do not involve content, i.e. are non-representional. Basic cognition does not involve meaning (the agents' interactions with the environment do not "say" anything about this environment), and it is non-propositional (it is not intrinsically true or false). ${ }^{36}$ This is not to deny that representation-based cognition actually occurs, but to stress that there is a vast realm of cognitive processes that do not involve content manipulation. These basic processes must be accounted for if a comprehensive understanding of cognition is to be established.

When it comes to high-level cognition, involving manipulation of representations and fixation of beliefs, it is secondary with respect to basic processes. It requires

${ }^{33}$ G. Ryle, The Concept of Mind, London 2009 [1949], p. 38.

${ }^{34}$ D.D. Hutto, E. Myin, op. cit., pp. $135 \mathrm{ff}$.

${ }^{35}$ Ibidem.

${ }^{36}$ This proposal is grounded in some significant advancements in robotics, made e.g. by R. Brooks and R.D. Beer (ibidem, pp. 41 ff.). Rather than basing his robot's actions on pre-planned models, Brooks had them perform tasks by frequently sampling features of their milieu and guiding their responses accordingly. This approach resulted in the robots' coherent, intelligent actions without generating their intermediary representations. Separate, centralised computational processes proved unnecessary. 
the development of scaffolded minds, erected on extensive basic minds. ${ }^{37}$ Content-involving cognition, resembling the central processes described by Fodor, requires the mastering of scaffolded practices, involving complex interactions with the environment and acquisition of language. In a nutshell, cognition is enaction (i.e. continuous bringing forth of an environment through interaction with it), which may potentially be followed by theorising (i.e. processing propositional content). To put this claim as succinctly as possible, "[w]e act before we think." 38

Enactivists are first to admit that although their approach is very good at explaining basic processes, it is still at loss when it comes to accounting for scaffolded cognition. However, in the past decades theories have emerged of the embodied basis of concept formation, which seem compatible with the enactive approach. The first is Mark Johnson's theory, ${ }^{39}$ according to which concepts are erected on the basis of image schemata, i.e. non-propositional, pre-conceptual structures abstracted from recurrent perceptuo-motor programmes. Image schemata are dynamic (they alter depending on the situation) and malleable (they may be adapted to novel situations). Although the most general of them are universal, individual sets of available schemata may vary depending on the history of one's perceptuo-motor experience. Image schemata could be seen as the minimum content mediating between basic and scaffolded cognition. They are the pre-conceptual representations of varieties of motion and sensation, out of which fully fledged concepts may be built. The notion of image schemata (or equivalent structures) underlies Lakoff and Johnson's theory of conceptual metaphor ${ }^{40}$ and Ronald Langacker's project of cognitive grammar, ${ }^{41}$ which derives all grammatico-lexical structures from perceptuo-motor schemata. The work undertaken by Vittorio Gallese with George Lakoff in the past decade aimed to show what may be the neurophysiological correlates of the formation of image schemata. ${ }^{42}$ Based on their theory of neural exploitation, according to which the mechanisms originally developed to control sensorimotor activity took on the role of controlling conceptual and linguistic processes, the authors proposed a model of how concepts of natural languages $(\operatorname{cog} s)$ may be abstracted from the sensorimotor stimuli provided by the interaction with the environment.

To summarise the above, according to the radical enactive account, the majority of cognitive processes do not involve formation and manipulation of representations. And when these representations do arise, it is not according to algorithms bestowed upon us with birth, but in relation to templates provided by our ongoing interaction with the world. These templates are dynamic and context-sensitive, and as such may change depending on particular conditions of enaction.

${ }^{37}$ Ibidem, pp. $151 \mathrm{ff}$.

${ }^{38}$ Ibidem, p. 121.

${ }^{39}$ See M. Johnson, The Body in the Mind. The Bodily Basis of Meaning, Imagination and Reason, Chicago 1987.

${ }^{40}$ G. Lakoff, M. Johnson, Metaphors We Live By, Chicago 1980.

${ }^{41}$ R.W. Langacker, Cognitive Grammar. A Basic Introduction, Oxford 2008.

42 V. Gallese, G. Lakoff, The Brain's Concepts: The Role of the Sensory-Motor System in Conceptual Knowledge, "Cognitive Neuropsychology" 2005, 22(3-4), pp. 455-479. 


\section{Religion according to enactivism?}

The foregoing summary of the enactive stance allows for an introductory reflection on how the notion of religion might be re-established. What follows is merely a list of points which need to be taken into consideration, and which stand in opposition to the cognitivist take on religion.

First, the search for a single, fixed evolutionary recipe for religion is most likely futile. The character of the coupling between an agent and its (physico-biologicocultural) milieu, and varying modes of enaction related to this coupling, will influence the emerging religious concepts differently. This does not mean that certain universal traits of religious representations cannot be postulated, but narrowing the discussion to these traits impoverishes the view on religion.

Moreover, as the character of the said coupling changes, so will, eventually, religious concepts. This may happen over centuries, over the span of a single lifetime or even of a single ritual. Where there may seem to be one religious concept, there may in fact be plenty of them, showing varying coherence with one another, depending on the situation.

Next, religion - just like cognition or mind - should be conceived as a process rather than a system of concepts. Constant emergence is its very nature. Undoubtedly, conceptual systems aimed at stabilising this precarious process are at work. Notions of orthodoxy and orthopraxy serve to regulate the current of experiences and representations that accompany religious processes. But codified doctrines form just a small part of what religion is, and they may become irrelevant in many contexts. ${ }^{43}$

Next, if contentful cognition is just "the tip of the cognitive iceberg," 44 one should not begin the search for cognitive explanations of religion at the level of content manipulation, but at the level of basic cognition. Through intentional interactions with the environment patterns of enaction emerge, which provide the basis for concept formation. The rudimentary perceptuo-motor experiences of actors immersed in an environment provide the grounds for the emergence of concepts of divinity, salvation and the like. Thus, these perceptuo-motor experiences must be studied carefully.

Importantly, if the foundations of religion are laid at the level of basic cognition and basic mentality, the notion of truth-value is initially irrelevant. First come enaction and experience. Only then can there be concept formation and, finally, evaluation of these concepts. Hence thinking about religion in terms of commitment to concepts that are untrue is an overestimation of intellectualism that characterises only a fairly small part of religion.

Next, the enactive approach forces one to reconsider the role of ritual in the emergence of religion. Ritual activities should be accounted for mainly as the enactive

${ }^{43}$ This last point has already been made by cognitivists Justin Barrett (J.L. Barrett, Theological Correctness, "Method and Theory in the Study of Religion" 1999, 199(11), pp. 325-339) and Harvey Whitehouse (H. Whitehouse, op. cit.), when they described the breaches of theological correctness, and the imagistic mode of religiosity, respectively. But their conclusions, grounded in staunch representationalism, do not seem to provide a profound enough interpretation of their observations.

${ }^{44}$ D.D. Hutto, E. Myin, op. cit., p. 46. 
basis for the formation of religious concepts, not only as their stabiliser. This does not mean that all forms of ritual enaction necessarily precede religious beliefs. There is clearly a feedback loop between religious representations and the forms of activity related to them. But one should accept that, to a considerable degree, it is the ritual that shapes religious concepts.

Once religious concepts are discussed, they should not be limited to concepts of entities (deities, ancestors and such), but should also include concepts of activities and processes. To give a general example, in different cultures various notions of soteriology take a central place, and soteriological goals are achieved through engaging in processes of various complexity and length. Diminishing the significance of those processes to focus only on the agents involved with them is unacceptable.

Finally, if religion is an emergent phenomenon, a precarious product of numerous interactions between humans and their milieu, it is virtually impossible to get a comprehensive understanding of what religion is by devising experiments and taking measurements in the lab. It is fine to study people's ability to memorise doctored narratives about gods, or to teach subjects meditation techniques to see how their brains react. But the outcomes of such pursuits will not bring us much closer to explaining religion, as religion taken out of its context is religion no more.

Before closing this discussion with a short example from Hindu ritual studies, a comment is needed on an existing alternative proposal within cognitive study of religion. Armin W. Geertz is known to contest the classical CSR stance, and to endorse embodied cognition. His assumptions, however, are not enactivist in spirit, and therefore his approach has to be seen as distinct from what is proposed here.

Devising his biocultural theory of religion, Geertz acknowledges that cognition is "embrained, embodied, encultured, extended and distributed." ${ }^{45} \mathrm{He}$ points to the interconnection between central nervous system (the limbic system and the pre-frontal cortex) and the endocrine system, to argue that "bodily processes and stimuli, emotions and feelings, higher order cognition... are connected" and therefore acting upon one element of this network affects the rest. ${ }^{46} \mathrm{He}$ observes that "manipulating" bodily states, e.g. during ritual, can "change and direct our minds." ${ }^{\text {"47 }}$ By making this observation, he stresses the importance of taking the sensorimotor experience into consideration. He also argues against the simplified cognitivist model, proposing instead to bravely deal with "a jumble of factors almost impossible to tease out into analytically meaningful units, theories and hypotheses." ${ }^{48}$ Yet still, his conclusions are based on a model of cognition different from the one summarised here.

Geertz advocates the thesis that cognition is simply extended, not extensive the brain's governance over the body allows the former to apply the latter as a tool necessary for the development of the mind. The mental, therefore, is not out there, as Ryle might put it, in the interaction between an agent and its milieu, but somewhere in there. It is a virtual object simply provided with - and developed through

\footnotetext{
${ }^{45}$ A.W. Geertz, op. cit., p. 304.

${ }^{46}$ Ibidem, pp. 306-307.

47 Ibidem, p. 307.

48 Ibidem, p. 305.
} 
- a reciprocal connection with external tools in the form of the body and its environment. Distributed cognition, i.e. cognition "inextricably enmeshed in emotional and semantic networks," ${ }^{49}$ is not enaction - it is supported by enaction. Finally, Geertz's view is essentially a representationalist one. He understands embodied cognition as "the use of perceptual, motor and spatial representations - representations of the body and the physical world - to facilitate cognition." ${ }^{50}$ There is no acknowledgement that multiple forms of intentional relations with the environment are contentless, that numerous guided responses to the environment actually do not involve representing.

To what extent these differences in basic assumptions influence the final interpretations of religious phenomena remains to be seen. Can starting off with basic, contentless cognition to look for sources or religious patterns of behaviour and thought bring results different from those obtained by starting off with embodied representations? Will treating the mind as an emergent process rather than an entity enmeshed in the body and its environment make any difference for the interpretation of culture in general and religion in particular? Or is applying a rigorous, radical enactive approach tantamount to adding an unnecessary, pretentious twist to an otherwise solid and fairly straightforward model? The answers to these questions can be sought as the enactive approach advances, and as its applicability within the study of religions is tested on concrete examples. The remaining part of the paper will be devoted to discussing an example that might provide an excellent opportunity to apply the enactive stance.

\section{Eat, digest, transform - modes of enaction in Suchitra Samanta's interpretation of bali}

The following example is based on Suchitra Samanta's analysis of the bali ritual performed at the Kälighät temple in Kolkata. ${ }^{51}$ Samanta's study took place between 1986 and 1992, and was based on observation of rituals, interviews with participants and analysis of textual sources. Bali (from the Sanskrit toot $b h r$ - to support, protect, maintain) is a sacrificial practice. In its most common form (known as pāthābali), a black goat is consecrated and decapitated. Its meat is then cooked and offered as a meal (bhog) to the goddess $K \bar{a} l \bar{l}$, who is believed to ingest it through the modality sight (darśan). After being consumed by the goddess, the meat is offered to the sacrifier, to be eaten as prasād (grace).

Interestingly, the incantations recited during consecration (baliprakaran) express the goat's desire to have its essence ( $b h \bar{a} v a)$, represented by blood, transformed into subuddhi (discriminative faculty of soteriological significance), and to have its animal bonds (paśupāśa) severed. A similar notion is present in tantric literature, describing

${ }^{49}$ Ibidem, p. 311.

50 Ibidem, p. 310.

${ }^{51}$ S. Samanta, The 'Self-Animal' and Divine Digestion: Goat Sacrifice to the Goddess Kālī in Bengal, "Journal of Asian Studies" 1994, 53(3), pp. 779-803. 
the transformation of the self, referred to as paśu (animal), through the process of $p \bar{a} k a$ (digestion/cooking) in the bowels of time ( $k \bar{a} l a)$. Notably, in mythical narratives $K \bar{a} l \bar{l}$ is depicted as a ferocious destroyer of demons, killing them through decapitation or ingestion of their blood. When these - and some other - factors are taken into consideration, it seems that pāthābali is a part of a global soteriological process, in which gradual refinement of the substance of the phenomenal world occurs. This process is construed in the categories of very basic activities, namely eating and digesting. As a part of this process, the discussed ritual is aimed at ridding the sacrifier of their ignorant animal/demonic nature (paśubhāva, äsurikbhāva) through the process of ingestion and digestion by a deity.

Notably, it is not the deity herself that is the most central element of the discussed set of concepts, but the process she effectuates. To put it crudely, the ritual is not about appeasing the goddess, but about enabling the process of cosmic transformation. Significant elements of this process (ingesting, digesting, defecating, being nourished, but also cooking, engaging in animal slaughter and warfare), experienced both during and outside of the ritual context, provide the enactive basis for the understanding of the entire system.

Another interesting element of the example concerns the roles ascribed to the actors in the ritual spectacle. As the process progresses, different identifications emerge and the roles change. The goat, through consecration, is identified with the sacrifier. As it is slain, it is reduced to paśubhāva, the sacrifier's ignorant, demonic essence. After being cooked it becomes the meal of the goddess and, as she symbolically digests it, it is turned into the divine essence (śakti, subuddhi), consubstantial with $K \bar{a} l \bar{l}$ herself. When consumed as prasād, it acts - as the divine principle - upon the sacrifier, inducing his or her transformation. All in all, at different points of the ritual the identities of the agent, the patient and the instrument change, depending on which part of the process becomes prominent. In other words, the process itself structures the relations between its elements.

To sum up, in the discussed example the groundwork for the entire conceptual system is found at the level of very basic processes and activities and the sensorimotor experience related to them. There is definitely feedback between these activities and doctrinal notions, which contributes to the wholesomeness of the system; without the enacted context, though, these notions remain incomprehensible. An important question that should be asked, however, is where religion begins in this puzzle. Is it at a level of complex conceptualisations, simply borrowing from the experience of eating and digesting to create a convincing, durable metaphor? Or at the level of the experience itself, series of contentless enactions that, through continuation and repetition, begin to produce pre-conceptual schemata, which in order offer themselves up to construal, resulting in the formation of concepts and narratives? I would opt for the second possibility, and suggest that, in the discussed example, the animal is not slain, cooked and eaten for religious reasons. It is the act of slaying, cooking and eating that awakens the urge for religious explanations. Certainly, these conceptualisations feed the loop and initiate subsequent rituals. But the loop continues due to the unstoppable need to act rather than due to belief in gods. Because first we are actors and experiencers, and only then are we thinkers. 


\section{Bibliography}

Atran S., In Gods We Trust. The Evolutionary Landscape of Religion, Oxford 2002.

Barrett J.L., Theological Correctness, "Method and Theory in the Study of Religion" 1999, 199(11), pp. 325-339.

Boyer P., Religion Explained. The Evolutionary Origins of Religious Thoughts, New York 2001.

Boyer P., The Naturalness of Religious Ideas: A Cognitive Theory of Religion, Berkeley 1994.

Di Paolo E.A., Rohde M., De Jaegher H., Horizons for the Enactive Mind: Values, Social Interaction, and Play [in:] Enaction. Toward a New Paradigm for Cognitive Science, J. Stewart, O. Gapenne, E.A. Di Paolo (eds.), Cambridge, MA 2010.

Fodor J.A., The Modularity of Mind: An Essay on Faculty Psychology, Cambridge, MA 1983.

Gallese V., Lakoff G., The Brain's Concepts: The Role of the Sensory-Motor System in Conceptual Knowledge, "Cognitive Neuropsychology" 2005, 22(3-4), pp. 455-479.

Geertz A.W., Brain, Body and Culture: A Biocultural Theory of Religion, "Method and Theory in the Study of Religion" 2010, 22, pp. 304-321.

Guthrie S., Faces in the Clouds. A New Theory of Religion, Oxford 1993.

Hutto D.D., Myin E., Radicalizing Enactivism. Basic Minds without Content, Cambridge, MA 2013.

Johnson M., The Body in the Mind. The Bodily Basis of Meaning, Imagination and Reason, Chicago 1987.

Lakoff G., Johnson M., Metaphors We Live By, Chicago 1980.

Langacker R.W., Cognitive Grammar. A Basic Introduction, Oxford 2008.

McCauley R.N., Lawson E.T., Bringing Ritual to Mind, Cambridge 2004.

Rosch E., Principles of Categorization [in:] Concepts. Core Readings, E. Margolis, S. Laurence (eds.), Cambridge, MA 1999, pp. 189-206.

Ryle G., The Concept of Mind, London 2009 [1949].

Samanta S., The 'Self-Animal'and Divine Digestion: Goat Sacrifice to the Goddess Kālì in Bengal, "Journal of Asian Studies" 1994, 53(3), pp. 779-803.

Sperber D., Explaining Culture. A Naturalistic Approach, Oxford 1996.

Tulving E., Episodic and Semantic Memory [in:] Organization of Memory, E. Tulving, W. Donaldson (eds.), New York 1972, pp. 381-402.

Varela F., Thompson E.T., Rosch E., The Embodied Mind. Cognitive Science and Human Experience, Cambridge 1991.

Whitehouse H., Arguments and Icons. Divergent Modes of Religiosity, Oxford 2000.

Whitehouse H., Lanman J.A., The Ties That Bind Us: Ritual, Fusion, and Identification, "Current Anthropology" 2014, 55(6), pp. 674-695. 